The American Heart Association training materials have been made available to countries all over the world and continue to be in great demand. They include training manuals, slides, films, workbooks, pamphlets, posters, and other educational tools.

In the past year, requests have been received from many countries for teaching faculty to help organize CPR training programs. Through our Visiting Teacher Program, we have been able to recruit highly trained personnel for this purpose. The American Heart Association helps to pay some of the costs. Developing countries that have a need for CPR assistance are encouraged to write to the American Heart Association for further particulars.

\section{Actions of the World Health Organizations (WHO) and the United Nations (UN) in Disasters}

\author{
S. William A. Gunn, M.D., M.S., F.R.C.S. $(C)^{*}$
}

\section{Introduction}

In essence, the United Nations Organization was born out of disaster to avert disaster. Be they the work of nature or of man, catastrophic emergencies are not rare occurrences and all studies indicate that they are increasing in frequency and severity.

Within the international community, the UN and its component organizations is only one of the three principal partners in disaster relief. The other are the NonGovernmental Organizations (NGO)-including the Voluntary Agencies (VOLAGS) - and the bilateral donor countries. Collaboration among these sectors is vital if international action is to be effective.

This article deals with the UN System only, and in particular with the role of the World Health Organization (WHO) in disaster relief and preparedness.

\section{Historical Background}

From its inception in the aftermath of the Second World War the United Nations decided that its various specialized agencies should have the capability to bring succor to those in need and to prevent a repetition of the disaster the world had just gone through. Mechanisms such as the United Nations Relief and Rehabilitation Agency (UNRRA), the United Nations International Children's Emergency Fund (UNICEF), later UNR WA (The United Nations Relief and Works Agency for Palestinian Refugees in the Near East/ were established specifically in response to emergencies, while others, like WHO and the Food and Agriculture Organization (FAO) formulated emergency procedures within their overall programs.

'Head, Emergency Relief Operations, World Health Organization, Ave Appia, 1211 Geneva 27, Switzerland. (Telephone 22-912777.) 
By the second half of the 1960's, the world as a whole was becoming better equipped with the institutional structures necessary to cope with disasters - both man-made and natural - wherever they might arise. Yet the situation could not be described as satisfactory or adequate. Political disturbances in Africa during this decade revealed the weaknesses in the capacity of the various organizations both public and private, to work together and to respond promptly to the major needs presented by these man-made emergencies. As the involvement of United Nations agencies in various human or natural disasters became progressively greater, the concern of the Member States with the need to improve methods of dealing with these situations began to manifest itself and the UN Economic and Social Council in 1965, agreed that the Resident Representative of the United Nations Development Program (UNDP) be assigned the coordinating role in the field. This is still one of his functions and has proven very useful. Other agencies may have their own representatives, such as the WHO Progam Coordinator in the country.

Despite these developments, however, the lack of readiness of the United Nations system as a whole to respond to emergencies was evident and was reiterated by the Secretary-General himself in 1971 in the following words: "The United Nations system as a whole - with the maior exception of UNICEF and to some extent WHO and FAO/WFP - is not equipped to provide emergency relief...."

In 1972, the Office of the Co-Ordinator of Disaster Relief (UNDRO) was established and up to the time of writing, the UN is continuing its efforts to increase its capability to face emergencies.

In the meantime, with the evolving world situation, the position of the organizations is changing. Those whose primary function had originally little to do with emergencies have found themselves in relief operations, while concurrently, agencies that were in essence established for emergency assistance have had to develop long-term programs. It is in fact becoming increasingly evident that a country's emergency problems and development programs are closely interlinked and must be seen - and acted upon-as a whole. More organizations and national programs are doing just that.

\section{The International Response in Emergencies}

To put intoeffect its charter and objectives, the UN acts through its agencies and organizations which work together as a system, each with its special field of competence, but collaborating and coordinating with the other for the common effort. Thus the task of UNHCR is to protect and assist refugees; of UNICEF to work in favour of mothers and children; of FAO and WFP to ensure adequate harvests and food for the growing population of the world. UNEP's field covers the human environment and UNESCO stands for educational, social and cultural protection. The World Health Organization (WHOl acts as the health arm of the United Nations, while the World Meteorological Organization (WMO) and the International Telecommunications Union (ITU) obviously have an important role in disasters.

Outside the UN, particular mention must be made of the International Red Cross which enjoys a special status and is of paramount importance in disasters and strife. It comprises the International Committee of the Red Cross (ICRCl and the League of Red Cross Societies (LRCS). Among important Non-Governmental Organizations (NGO) active in this field are the World Council of Churches, Caritas Internationalis, Oxfam and many others which, as Voluntary Agencies (VOLAGS) bring invaluable assistance to countries in need. The figure summarizes the situation.

\section{UN Response to Emergencies}

How does a UN agency intervene in an emergency?

When a major disaster occurs which is beyond the capacity or resources of a country to cope with, a state of emergency is declared by the authorities of that country and outside assistance is requested.

The authorities of the stricken country may approach the UN/HQ or UNDRO or one of the Agencies, requesting assistance. Depending on the nature and magnitude of the disaster, the response may take several forms.

If, for example, the emergency is a serious epidemic, usually WHO alone is involved. The WHO Program Coordinator in the country assesses the situation and, with the Regional Office advises on the emergency action. Based on this, the Organization immediately provides the services, supplies and other assistance as required. UNDRO is informed but not necessarily involved. WHO's action may be through its own emergency funds and facilities, or it may seek the direct contribution of known donors or other friendly countries or call upon health specialists from outside the Organization.

If the same emergency requires funds that are beyond the scope of the above-mentioned direct mechanism, UNDRO makes an appeal for contributions in cash and in kind to meet the immediate needs. If other agencies are in- 


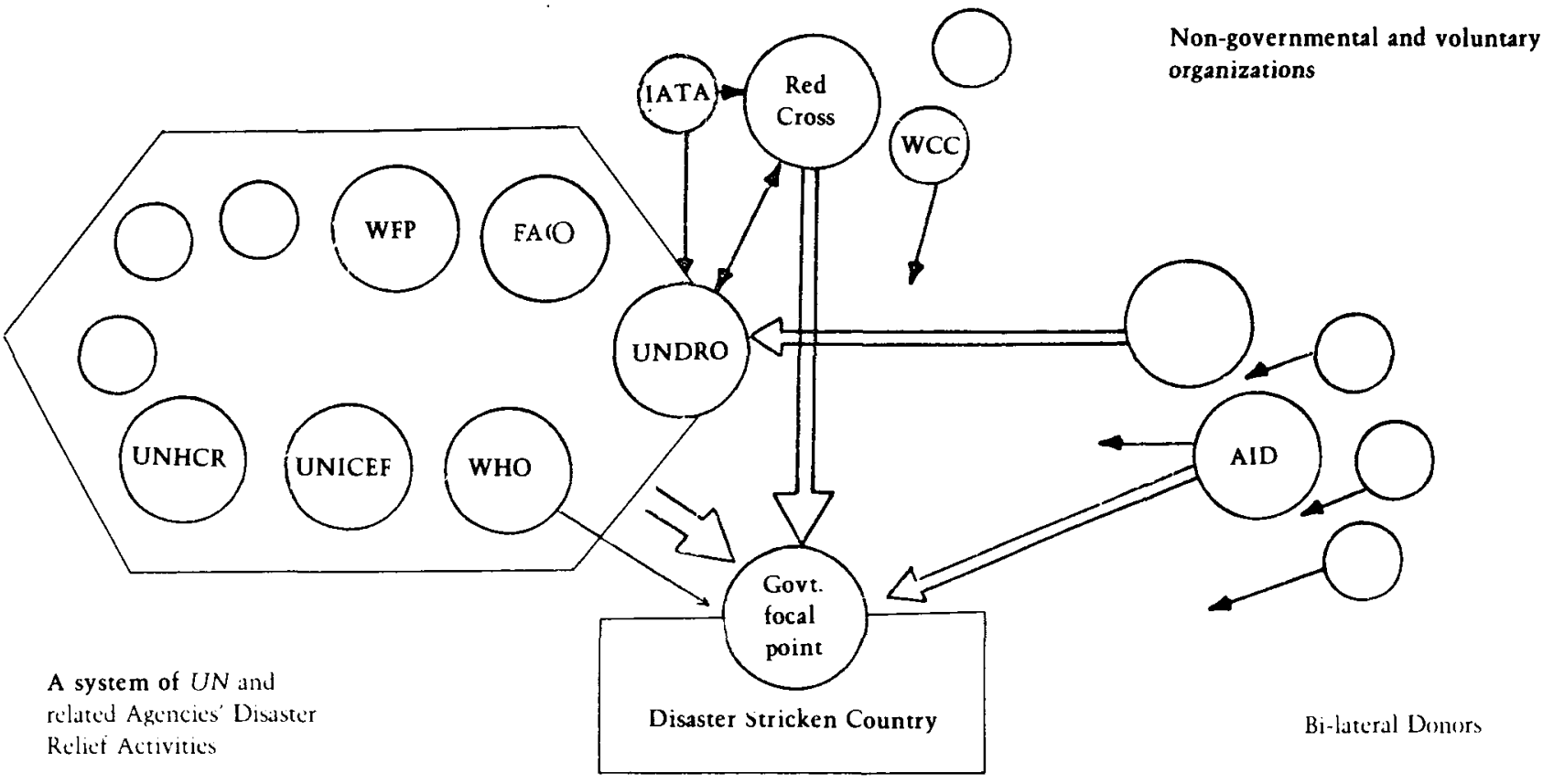

Figure

volved, e.g., food by FAO besides medicines and health services from WHO, UNDRO coordinates the multiagency involvement.

\section{WHO in Emergency Operations}

Within the United Nations system, WHO is the focal point of competence and authority for all health matters related to emergency relief and disaster preparedness. In emergencies or disasters where overall relief activities are being organized by other United Nations agencies or coordinated by UNDRO, coordination of emergency health measures and liaison with the other agencies is assured by the WHOEmergency Relief Operations.

The involvement of the World Health Organization in emergencies dates from the inception of the Organization. In the early years this aimed at furnishing aid in emergencies and consisted mainly of immediate action to combat epidemics and provide relief to victims of a calamity. Over the years, this ad hoc immediate reponse has been strengthened by planned action and preventive measures.
Emergencies and disasters are by definition unexpected events and therefore do not always respond to the usual patterns of planning. Nevertheless, preparedness for emergencies and their damaging effects is possible and, while retaining flexibility of action in face of unforeseen emergencies, WHO has established a medium-term program to promote preparedness and minimize the effect of disasters on health. Thus WHO's thrust in disasters has gradually become two-pronged: on the one hand, emergency relief and assistance in case of epidemics and other calamities; on the other hand promoting technical cooperation among Member States for prevention, planning and preparedness for disasters.

The authority of WHO to take action in emergencies is derived from its Constitution. Article 2 (d) states that one of the functions of the Organization shall be to furnish necessary aid in emergencies. Another article calls for studies and research on emergency problems, and as a resolution at the World Health Assembly in 1981 emphasized the strengthening of prevention and preparedness.

WHO's activities extend to the health aspects of all disasters, whether natural, technological, due to strife or re- 
sulting from epidemics.

Health is an integral part of development. A disaster, whether natural or man-made, usually wipes out, in one tragic stroke, a country's laboriously constructed health facilities and expensive development efforts.

Torespond to the needs of the Member States, to play its leading role in health within the UN system, and to achieve its objectives, WHO carries out the following activities in disaster management:

- It provides relief in emergencies and promotes disaster management and preparedness for catastrophes;

- It procures and makes available urgently needed medications and medical supplies to disaster-stricken peoples;

- It generates funds from bilateral, multilateral and non-governmental sources for emergency work;

- It promotes capability in disaster management for preparedness and prevention, amd collaborates with Member States and Regional Offices in establishing or developing national self-reliance in face of disasters;

- On WHO's impetus, disaster research centers are being established in academic as well as managerial institutions. A principal strategy for WHO's objective includes collaboration with such centers as the Ross Institute in London and the University of Louvain Disaster Research Unit. Fellows from disaster-prone countries are trained in emergency work, and research on disaster epidemiology is carried out. The aim is to have basic information on disasters and to train key persons in countries or regions at risk who can generate organizational and operational capability todeal with emergencies.

- Meetings, seminars and training courses are held with and for senior disaster personnel from developing countries;

- Besides the in-house Standing Emergency Task Force, and in collaboration with the WHO Regions, a worldwide network of action-oriented disaster specialists is established to act as Expert Advisory Panel and to be available for emergency health work on immediate notice.

- With international collaboration well-documented Country Fact Sheets and Disaster Profiles are compiled for disaster preparedness. WHO also issues appropriate manuals, establishes standards and makes available simple guides for various types of emergencies.
Overall coordination of WHO's emergency measures is ensured with those of the UN system, the International Committee of the Red Cross, the League of Red Cross Societies, Oxfam, and other organizations such as the International Society for Disaster Medicine.

With these and other appropriate measures the World Health Organization strives to bring emergency technical assistance to disaster-stricken countries, to assist in reconstruction, and to promote preparedness against calamities, within the WHO concept of providing health for all. 